\title{
The Protective Effect of Sonneratia apetala Fruit Extract on Acetaminophen-Induced Liver Injury in Mice
}

\author{
Jingjing Liu, ${ }^{1}$ Dandan Luo, ${ }^{1}$ Yulin Wu, ${ }^{1}$ Changjun Gao ${ }^{D},{ }^{2}$ Guosheng Lin $\mathbb{D}^{1},{ }^{1}$ Jinfen Chen, \\ Xiaoli Wu $\left(\mathbb{D},{ }^{3}\right.$ Qian Zhang, ${ }^{2,4}$ Jian Cai $\left(\mathbb{D},{ }^{2,4}\right.$ and Ziren Su $\oplus^{1}$ \\ ${ }^{1}$ Mathematical Engineering Academy of Chinese Medicine, Guangdong Provincial Key Laboratory of New Drug Development and \\ Research of Chinese Medicine, Guangzhou University of Chinese Medicine, Guangzhou 510006, China \\ ${ }^{2}$ Guangdong Provincial Key Laboratory of Silviculture, Protection and Utilization, Guangzhou 510520, China \\ ${ }^{3}$ Postdoctoral Programme, The Second Affiliated Hospital of Guangzhou University of Chinese Medicine, Guangzhou 510006, China \\ ${ }^{4}$ Guangdong Academy of Forestry, Guangzhou 510520, China
}

Correspondence should be addressed to Jian Cai; caijian@sinogaf.cn and Ziren Su; suziren@gzucm.edu.cn

Received 9 January 2019; Revised 14 April 2019; Accepted 9 June 2019; Published 19 June 2019

Academic Editor: Claudia Di Giacomo

Copyright (C) 2019 Jingjing Liu et al. This is an open access article distributed under the Creative Commons Attribution License, which permits unrestricted use, distribution, and reproduction in any medium, provided the original work is properly cited.

\begin{abstract}
Acute liver injury is a common consequence of taking overdose of acetaminophen (APAP). The aim of this study was to evaluate the antioxidant activity and hepatoprotective effect of a mangrove plant Sonneratia apetala fruit extract (SAFE) on APAP-induced liver injury in mice. Mice were orally pretreated with SAFE $(100,200$, and $400 \mathrm{mg} / \mathrm{kg})$ daily for one week. The control and APAP groups were intragastrically administered with distilled water, and NAC group was treated with N-Acetyl-L-cysteine (NAC) before APAP exposure. The results manifested that SAFE significantly improved survival rates, attenuated hepatic histological damage, and decreased the alanine aminotransferase (ALT) and aspartate aminotransferase (AST) levels in serum in APAP-exposed mice. SAFE treatment also increased glutathione (GSH) level and glutathione peroxidase (GSH-Px) activity, enhanced catalase (CAT), and total antioxidant capacity (T-AOC), as well as reducing malondialdehyde (MDA) level in liver. In addition, the formation of tumor necrosis factor-alpha (TNF- $\alpha$ ), interleukin 6 (IL-6), and elevation of myeloperoxidase (MPO) in APAP-exposed mice were inhibited after SAFE treatment. And SAFE also displayed high DPPH radical scavenging activity and reducing power in vitro. The main bioactive components of SAFE such as total phenol, flavonoid, condensed tannin, and carbohydrate were determined. The current study proved that SAFE exerted potential protective effect against APAP-induced acute liver injury, which might be associated with the antioxidant and anti-inflammatory activities of SAFE.
\end{abstract}

\section{Introduction}

Acetaminophen ( $\mathrm{N}$-acetyl-para-aminophenol, APAP), a classical antipyretic and analgesic, is widely used to treat cold and fever clinically all over the world, but overdose of APAP engenders acute liver injury and even more severe liver failure [1]. According to a report, APAP-induced hepatotoxicity is the primary cause of acute liver injury and results in about $50 \%$ of all the cases in developed countries [2]. The basic mechanism of acute liver injury induced by APAP consists of reactive metabolites production, GSH depletion, and protein adducts generation that further contribute to the dysfunction of mitochondria, the production of peroxynitrite, nuclear DNA fragmentation and ultimately lead to hepatocellular necrosis $[3,4]$. The clinical antidote to APAP toxicity is NAcetyl-L-cysteine (NAC), which is an available nonspecific antioxidant that alleviates oxidative stress in the manner of direct obliteration or serves as a glutathione precursor to afford sufficient glutathione to combine with $\mathrm{N}$-acetyl-pbenzoquinone imine (NAPQI) $[5,6]$. NAC is considered as a safe and effective antidote for hepatotoxicity caused by APAP overdose and can be optimally used within $8 \mathrm{~h}$ [7]. However, NAC also has some side effects, including headache, nausea, vomiting, diarrhea, and flatulence [6]. Hence, it is still a focused issue to be solved that to develop safe and effective drugs against acute liver injury caused by APAP.

In recent years, the use of plants in treating diseases has attracted more attentions due to economic price as well 
as little side effects $[8,9]$. Sonneratia apetala (S. apetala), also called Keora in local, is a member of the Lythraceae belonging to mangrove, which widely exists in Sundarbans (the world's largest mangrove forest) and the coastal regions in Bangladesh, India, Myanmar, Malaysia, New Guinea, China, etc. [10-12]. As an exotic mangrove species introduced from India, Bengal, and Sri Lanka [13], S. apetala mainly distributes in the southeast coastal areas in China [14] and serves as the dominant species of mangroves because of its high adaptability, rapid growth, high seed setting rate, and other characteristics [15]. The fruit of S. apetala is edible and generally made into food with multifarious preparing processes by people in coastal Bangladesh, India, Myanmar, and China, which are also processed into market products such as sour sauce, fermented juice, soft drinks, and so on $[16,17]$. Moreover, it also exerts pharmaceutical value and is often used as medicine to treat illnesses including hepatitis, dysentery, bruise, etc. by people in local [16-19]. The fruit of S. apetala is applied to curing sprain and cough in China, and it is also used as medicine for internal diseases along with leaf and flower [20]. It has been proved that the fruits and barks of $S$. apetala display the efficacy of curing wheezing, fevers, ulcers, swellings, sprains as well as hemorrhage [21]. Moreover, S. apetala is used as anti-inflammatory agents to treat gastrointestinal disorders such as dysentery, diarrhea, and stomachache by folk medicinal healers in Bangladesh $[16,17]$. Extracts of $S$. apetala fruits have showed a wide range of biological activities, including antioxidant, antidiabetic, anticancer, and antibacterial activities $[10,22]$. The main bioactive constituents of $S$. apetala are polyphenols, flavonoids, tannins, and carbohydrates, which contribute to its antioxidant activity and make it to be a potential source of natural antioxidants [11,23-26]. Additionally, triterpenes, steroids, carboxylic acids, and lactones also contribute to S. apetala biological properties $[10,18,26]$. Liver damage in most situations involves oxidative stress that can directly participate in liver pathologies and their processes [27]. Overdose APAP overwhelms the hepatic detoxification process and depletes GSH, which leads to oxidative stress and further contributes to liver injury [28]. Therefore, antioxidants and antioxidant-rich plant may be used as therapeutic agents for liver damage [27, 29, 30]. An increasing body of evidences have proved that alleviating oxidative stress and inflammation would be a potential way to attenuate acute liver injury induced by APAP [31-33]. Hence, as a potential natural antioxidant, $S$. apetala may play an important role in treating APAP-induced acute liver injury. Although the antioxidant and anti-inflammatory activities of $S$. apetala have been reported, its hepatoprotective activity has rarely been investigated. Therefore, the aim of the present study was to assess the antioxidant activity and hepatoprotective effect of S. apetala fruit extract (SAFE) against APAP-induced acute liver injury in mice.

\section{Materials and Methods}

2.1. Materials. The fresh $S$. apetala fruits of the mangrove plant were collected from Nansha Coast Wetland
Scenic spot, Guangzhou, China. APAP (CAS: 103-90-2), NAC (CAS: 616-91-1), and ascorbic acid (CAS:50-81-7) were obtained from Guangzhou Feibo Biological Technology Co., Ltd. 1,1-Diphenyl-2-picryl-hydrazyl (DPPH, CAS:1898-66-4), (+)-Catechin (CAS:154-23-4), and Folin-Ciocalteu reagent (CAS:NONE6060) were purchased from Shanghai Macklin Biochemical Co., Ltd. Potassium ferricyanide (CAS:1374666-2), trichloroacetic acid (CAS:76-03-9), ferric trichloride (CAS:10025-77-1), and vanillin (CAS:121-33-5) were obtained from Damao Chemical Reagent Factory China. Gallic acid was purchased from Wenzhou Ouhai Fine Chemical Co., Ltd. (Zhejiang, China). The alanine aminotransferase (ALT) detection kit (C009-2), aspartate aminotransferase (AST) detection kit (C010-2), glutathione (GSH) assay kit (A006-2), glutathione peroxidase (GSH-Px) assay kit (A005), catalase (CAT) assay kit (A007-1), total antioxidant capacity (T-AOC) assay kit (A015), malondialdehyde (MDA) assay kit (A0031), and myeloperoxidase (MPO) detection kit (A044) were purchased from Nanjing Jiancheng Bioengineering Institute (Nanjing, China). The enzyme linked immunosorbent assay (ELISA) kits for determination of inflammatory cytokines TNF- $\alpha$ (E-20219) and IL-6 (E-20012) were obtained from Beijing Andy Huatai Biological Technology Co., Ltd. The other analytical reagents and chemicals were obtained from Tianjin Zhiyuan Chemical Reagent Co., Ltd.

2.2. Extraction of the Fruits of S. apetala. The fresh S. apetala fruits $(5 \mathrm{~kg}$ ) were collected and rinsed thoroughly before extraction and then extracted with 2 -fold boiled water for $3 \mathrm{~h}$; occasional stirring was performed to prevent from burning. Extract was obtained and concentrated to $1.1 \mathrm{~L}$ after filtration in vacuum. Then, the concentrated sample was freeze-dried. The SAFE was obtained and stored at $4^{\circ} \mathrm{C}$ for further analysis.

\subsection{Chemical Compositions Analysis}

2.3.1. Phytochemical Analysis. The qualitative phytochemical assays were carried out to evaluate the presence of flavonoids, phenols, tannins, saponins, cardiac glycosides, steroids, alkaloids, anthraquinones, organic acids, carbohydrates, protein, and amino acids in SAFE using standard procedures $[10,34]$.

2.3.2. Determination of Total Phenol Content. The total phenol content of SAFE was determined by Folin-Ciocalteu reagent [35] using gallic acid as the standard. Briefly, $150 \mu \mathrm{L}$ samples in different concentrations were mixed with $750 \mu \mathrm{L}$ of Folin-Ciocalteu reagent and $600 \mu \mathrm{L}$ of sodium carbonate $(7.5 \%, w / v)$. Then the mixture was incubated at $40^{\circ} \mathrm{C}$ for 30 min and we measured the absorption at $760 \mathrm{~nm}$.

2.3.3. Determination of Total Flavonoid Content. The measurement of total flavonoid content was performed by the aluminium chloride colorimetric method [36, 37]. In brief, the total volume of reaction solution was $2 \mathrm{~mL}$ including 200 $\mu \mathrm{L}$ sample or standard ((+)-catechin), $60 \mu \mathrm{L}$ of $5 \% \mathrm{NaNO}_{2}$ and $10 \% \mathrm{AlCl}_{3}, 400 \mu \mathrm{L}$ of $\mathrm{NaOH}(1 \mathrm{M})$, and $480 \mu \mathrm{L}$ distilled water. The absorbance measurements were performed at 510 nm. 
2.3.4. Determination of Total Condensed Tannins Content. The detection of total tannins content in SAFE was carried out according to the reported method [30] using (+)-catechin as a standard. Briefly, $0.5 \mathrm{~mL}$ sample or standard was mixed with 3 $\mathrm{mL}$ of vanillin $(4 \%, w / v)$ in methanol and $1.5 \mathrm{~mL}$ concentrated $\mathrm{HCl}$ following stand at room temperature for $15 \mathrm{~min}$. Then the absorbance at $500 \mathrm{~nm}$ was determined against methanol as a blank.

2.3.5. Determination of Total Carbohydrate Content. The total carbohydrate content of SAFE was determined by phenolsulfuric acid method according to reported method [38, 39] using glucose as the standard. In brief, $2 \mathrm{~mL}$ of sample solution was mixed with $1 \mathrm{~mL}$ of phenol $(5.0 \%, w / v)$ and $5 \mathrm{~mL}$ of concentrated sulfuric acid. Then the absorbance of mixture was recorded at $490 \mathrm{~nm}$ after standing at room temperature for $15 \mathrm{~min}$.

\subsection{Assay of Antioxidant Activity of SAFE In Vitro}

2.4.1. DPPH Radical Scavenging Activity. The scavenging activity of DPPH radical was determined by reported method [40]. Briefly, $1 \mathrm{~mL}$ of sample solution with different concentrations $(20,40,60,80,100$, and $120 \mu \mathrm{g} / \mathrm{mL})$ was added to 2 $\mathrm{mL}$ of freshly prepared $\mathrm{DPPH}$, mixing thoroughly, and the mixture was incubated at room temperature for $30 \mathrm{~min}$ in the dark. The absorbance of mixture was recorded at $517 \mathrm{~nm}$. The DPPH radical scavenging activity was calculated with the following equation:

DPPH radical scavenging activity (\%)

$$
=\left(1-\frac{\mathrm{A}_{0}-\mathrm{A}_{1}}{\mathrm{~A}_{2}}\right) \times 100 \%
$$

where $A_{0}$ was the absorbance of a mixture of sample and DPPH solution, $A_{1}$ was the absorbance of sample solution with ethanol, and $\mathrm{A}_{2}$ was the absorbance of a mixture of DPPH solution and distilled water. The ascorbic acid $(\mathrm{Vc})$ was served as positive control.

2.4.2. Reducing Power. The reducing power of SAFE was measured according to the reported method [41]. $2.5 \mathrm{~mL}$ of phosphate buffer (0.2 M, pH 6.6) and $2.5 \mathrm{~mL}$ of potassium ferricyanide $(1.0 \%, w / v)$ were mixed with different concentrations SAFE solution and incubated at $50^{\circ} \mathrm{C}$ for $20 \mathrm{~min}$. Then $2.5 \mathrm{~mL}$ trichloroacetic acid $(10 \%, w / v)$ was added to the mixture prior to centrifugation at $1500 \mathrm{~g}$ for $10 \mathrm{~min}$. The 2.5 $\mathrm{mL}$ of supernatant was mixed with $0.5 \mathrm{~mL}$ of ferric trichloride $(1.0 \%, w / v)$ and $2.5 \mathrm{~mL}$ of distilled water, and the absorbance was detected at $700 \mathrm{~nm}$. Vc was used as positive control.

\subsection{Assay of Hepatoprotective Effect of SAFE In Vivo}

2.5.1. Animals. Male Kunming mice ( 8 weeks old) were purchased from Guangzhou University of Chinese Medicine. These mice were domesticated under the environment with free access to food and water (temperature: $18 \sim 29^{\circ} \mathrm{C}$, humidity: $40 \% \sim 70 \%, 12 \mathrm{~h}$ light and dark cycle) for 1 week before experiment. All experimental procedures were performed according to the Ethics Committee for the Welfare of Experimental Animals of Guangzhou University of Chinese Medicine (no. 2016047).

2.5.2. Experimental Design. The APAP-induced liver injury in mice was established by injecting $220 \mathrm{mg} / \mathrm{kg}$ of APAP according to the publications $[2,42]$. All the mice were randomly assigned to the following six groups ( $n=15 /$ group): (1) control group, (2) APAP group (APAP, $220 \mathrm{mg} / \mathrm{kg}$ ), (3) NAC group (220 mg/kg APAP + $200 \mathrm{mg} / \mathrm{kg} \mathrm{NAC),} \mathrm{(4)}$ low dose of SAFE group (220 mg/kg APAP + $100 \mathrm{mg} / \mathrm{kg}$ SAFE), (5) middle dose of SAFE group (220 mg/kg APAP $+200 \mathrm{mg} / \mathrm{kg} \mathrm{SAFE}$ ), and (6) high dose of SAFE group (220 mg/kg APAP + $400 \mathrm{mg} / \mathrm{kg}$ SAFE). Different doses of SAFE were dissolved in suitable amount of distilled water. APAP was dissolved in normal saline solution before being intraperitoneally administered to mice. And the NAC, serving as positive control, accepted equal treatment with SAFE. For groups 1 and 2, distilled water was administered orally every day for 7 days. At the same time, group 3 were treated with NAC. For group 4-6, mice were intragastrically given 100,200 , and $400 \mathrm{mg} / \mathrm{kg}$ of SAFE, respectively. $4 \mathrm{~h}$ after the last administration, all the mice were given APAP by intraperitoneal injection, while the control group was injected with the same volume of normal saline. $12 \mathrm{~h}$ after the APAP challenge, blood samples were collected from the mice eye socket vein and centrifuged ( $3000 \mathrm{rpm}, 4^{\circ} \mathrm{C}, 10 \mathrm{~min}$ ) to obtain serum. Then mice were sacrificed and liver tissues were harvested, washed with normal saline three times, and stored at $-80^{\circ} \mathrm{C}$ for further analysis.

2.5.3. Survival Analysis. In order to estimate mortality in APAP-exposed mice, another 90 mice were treated as above. All the groups were fasted for $12 \mathrm{~h}$ and subsequently fed normal diet. The survival situations of mice were recorded every $12 \mathrm{~h}$ for 5 days to obtain survival rates.

2.5.4. Histopathology. The collected liver tissues from all the groups were fixed in $4 \%$ paraformaldehyde, dehydrated and embedded in paraffin, sectioned at $5 \mu \mathrm{m}$ thickness, and dyed with hematoxylin and eosin $(\mathrm{H} \& \mathrm{E})$ routinely. Liver histopathologic changes were captured with an optical microscope at 200× magnification (E100, Nikon Corporation).

2.5.5. ALT and AST Levels Assay. The blood samples were kept at room temperature for $2 \mathrm{~h}$ and then centrifuged at $3,000 \mathrm{rpm}$ for $10 \mathrm{~min}$ at $4^{\circ} \mathrm{C}$ to obtain serum. ALT and AST levels in the serum were quantified using commercial kits.

2.5.6. GSH, GSH-Px, CAT, T-AOC, and MDA Assay. The liver tissues were thawed and homogenized in 9-fold ( $\mathrm{g}: \mathrm{mL}$ ) of ice-cold normal saline. The homogenate was centrifuged at $3000 \mathrm{rpm}$ for $10 \mathrm{~min}$ at $4^{\circ} \mathrm{C}$ to obtain supernatant. The levels of GSH, GSH-Px, MDA, CAT, and T-AOC in supernatant were measured using commercial kits according to the manufacturer's protocols. 
TABLE 1: Phytochemical screening of fruit extract of S. apetala.

\begin{tabular}{lcc}
\hline No. & Tests & Extract \\
\hline 1 & Flavonoids & + \\
2 & Phenols & + \\
3 & Tannins & + \\
4 & Saponins & - \\
5 & Cardiac glycosides & - \\
6 & Steroids & + \\
7 & Alkaloids & + \\
8 & Anthraquinones & - \\
9 & Organic acids & + \\
10 & Carbohydrates & + \\
11 & Protein and amino & + \\
\hline
\end{tabular}

+: present; -: absent.

2.5.7. MPO Activity Assay. The liver samples were weighted accurately and homogenized with precold homogenization medium (1:19). Then, the MPO activity in liver tissue was measured using commercial kit according to the manufacturer's method.

2.5.8. TNF- $\alpha$ and IL-6 Levels Assay. Liver tissues were weighted and homogenized with 9-fold ice-cold PBS $(\mathrm{pH}$ $7.4)$ at $2-8^{\circ} \mathrm{C}$. Thereafter, liver tissue homogenates were centrifuged at the speed of $3000 \mathrm{rpm}$ for $20 \mathrm{~min}$. The assay of TNF- $\alpha$ and IL- 6 was performed as followings. Hepatic homogenate samples and standards were added to the ELISA plates followed by incubation for $30 \mathrm{~min}$ at $37^{\circ} \mathrm{C}$. Following washing for 5 times by wash solution, every well was incubated with $50 \mu \mathrm{L}$ of HRP-conjugate reagent at $37^{\circ} \mathrm{C}$ for $30 \mathrm{~min}$ followed by washing for 5 time as well. Subsequently, $50 \mu \mathrm{L}$ of chromogen solution A and B was, respectively, added to each well followed by incubation for $15 \mathrm{~min}$ at $37^{\circ} \mathrm{C}$. Finally, $50 \mu \mathrm{L}$ of stop solution was added to the wells and the absorbance was read at $450 \mathrm{~nm}$.

2.5.9. Statistical Analysis. All data were represented as mean \pm SD. The statistical analysis was performed by Statistical Product and Service Solutions software 23.0 (SPSS Inc., USA). One-way analysis of variance (ANOVA) followed by the multiple comparisons of Least Significant Difference (LSD) test was used for all the data analysis. The survival analysis was determined by Kaplan-Meier curve and log-rank MantelCox test. In this study, $p<0.05$ was considered as a significant difference.

\section{Results}

3.1. The Phytochemical Composition Analysis of SAFE. In this study, the dried extraction was obtained from the fruits of S. apetala. The yield of SAFE was approximately $1.28 \%$ $(w / w)$.The phytochemical screening and chemical composition of SAFE are shown in Tables 1 and 2, respectively. The results showed the presence of flavonoids, phenols, tannins, steroids, alkaloids, organic acids, carbohydrates, protein, and amino acids on SAFE. The total phenol, flavonoid, and condensed tannin content on SAFE were expressed in $\mathrm{mg}$ gallic acid equivalent per $g$ of extract and $\mathrm{mg}(+)$-catechin equivalent per $g$ of extract, respectively. SAFE exhibited the total phenol content of $143.64 \pm 6.49 \mathrm{mg} / \mathrm{g}$, the total flavonoid content of $20.93 \pm 0.79 \mathrm{mg} / \mathrm{g}$, and the total condensed tannin content of $5.47 \pm 0.25 \mathrm{mg} / \mathrm{g}$. It was also found that the total carbohydrate content of SAFE was $23.94 \pm 0.50 \%$.

3.2. Antioxidant Activity In Vitro. The DPPH radical scavenging activity of SAFE is shown in Figure 1(a). SAFE revealed strong scavenging activity on DPPH with the maximum suppression of $93.91 \%$ at the concentration of $120 \mu \mathrm{g} / \mathrm{mL}$, and the $\mathrm{IC}_{50}$ was measured to be $23.65 \mu \mathrm{g} / \mathrm{mL}$. As shown in Figure 1(b), the reducing power of the tested samples steadily raised with the increasing sample concentration. At $500 \mu \mathrm{g} / \mathrm{mL}$, the reducing power was 0.52 for SAFE.

\subsection{The Hepatoprotective Effect of SAFE In Vivo}

3.3.1. SAFE Attenuated APAP-Induced High Mortality Rate. As displayed in Figure 2, the survival rate at $12 \mathrm{~h}$ was about $53.33 \%$ and finally dropped to only $40 \%$ at $120 \mathrm{~h}$ after APAP exposure in APAP group. Interestingly, the survival rate of NAC-treated mice was $73.33 \%$ at $12 \mathrm{~h}$ and maintained the same until $120 \mathrm{~h}$. And SAFE treatment (100, 200, and 400 $\mathrm{mg} / \mathrm{kg})$ significantly increased the survival rates $(60 \%, 80 \%$, and $93.33 \%)$ at $120 \mathrm{~h}$ compared with APAP group $(p<0.05)$.

3.3.2. SAFE Relieved Histopathological Damage Induced by $A P A P$. As shown in Figure 3, hepatic cells of control group expressed normal histology. However, hepatic sections of APAP-treated mice showed hepatocyte necrosis, inflammation cell infiltration, and congestion in central vein while compared with control group. The histopathological damage was alleviated with SAFE and NAC treatment.

3.3.3. SAFE Mitigated APAP-Induced Hepatotoxicity. The protective effect of SAFE on APAP-induced liver injury was evaluated by measuring the ALT and AST levels in serum. The ALT (Figure 4(a)) and AST (Figure 4(b)) levels in APAP group were $307.67 \pm 40.10 \mathrm{U} / \mathrm{L}$ and $151.53 \pm 8.92 \mathrm{U} / \mathrm{L}$ after APAP exposure, respectively, which were 19.93-fold and 11.96-fold higher than that of the control groups, respectively. However, SAFE treatment dose-dependently inhibited the ALT and AST levels. Compared with APAP group, ALT levels in 100,200 , and $400 \mathrm{mg} / \mathrm{kg}$ groups declined to $43.16 \pm 16.78$ $\mathrm{U} / \mathrm{L}, 27.42 \pm 19.66 \mathrm{U} / \mathrm{L}$, and $17.65 \pm 3.95 \mathrm{U} / \mathrm{L}$, respectively, and the AST levels declined to $111.73 \pm 8.08 \mathrm{U} / \mathrm{L}, 50.08 \pm 7.06 \mathrm{U} / \mathrm{L}$, and $21.72 \pm 1.97 \mathrm{U} / \mathrm{L}$, respectively. Among them, $400 \mathrm{mg} / \mathrm{kg}$ of SAFE treatment displayed the best effects with the similar ALT and AST levels as that of control group.

3.3.4. SAFE Restrained APAP-Induced Liver Oxidative Stress. As shown in Figure 5, $12 \mathrm{~h}$ after APAP injection, GSH level and GSH-Px activity in liver decreased by $87.88 \%$ and $29.75 \%$ in APAP group when compared with control group $(p<0.01)$. 
TABLE 2: The total phenols, flavonoids, condensed tannins, and carbohydrate content for SAFE.

\begin{tabular}{lcccc}
\hline Content & $\begin{array}{c}\text { Total phenols } \\
\left(\mathrm{mg} / \mathrm{g}^{\mathrm{ab}}\right)\end{array}$ & $\begin{array}{c}\text { Total flavonoids } \\
\left.(\mathrm{mg} / \mathrm{g})^{\mathrm{ac}}\right)\end{array}$ & $\begin{array}{c}\text { Total } \\
\text { Condensed } \\
\text { tannins }\left(\mathrm{mg} / \mathrm{g}^{\mathrm{ac}}\right)\end{array}$ & $\begin{array}{c}\text { Total } \\
\text { carbohydrates } \\
(w / w, \%)\end{array}$ \\
\hline SAFE & $143.64 \pm 6.49$ & $20.93 \pm 0.79$ & $5.47 \pm 0.25$ & $23.94 \pm 0.50$ \\
\hline
\end{tabular}

${ }^{\mathrm{a}}$ Average of 3 determinations, mean $\pm \mathrm{SD} .{ }^{\mathrm{b}}$ Gallic acid and ${ }^{\mathrm{c}}(+)$-Catechin equivalent in $\mathrm{mg} / \mathrm{g}$ of the extract.

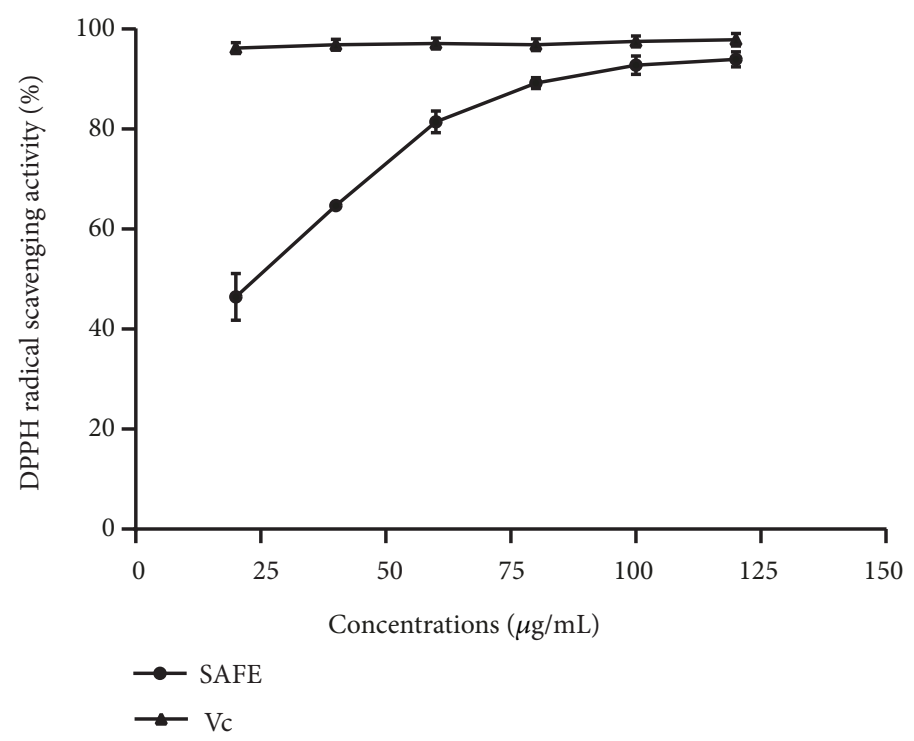

(a)

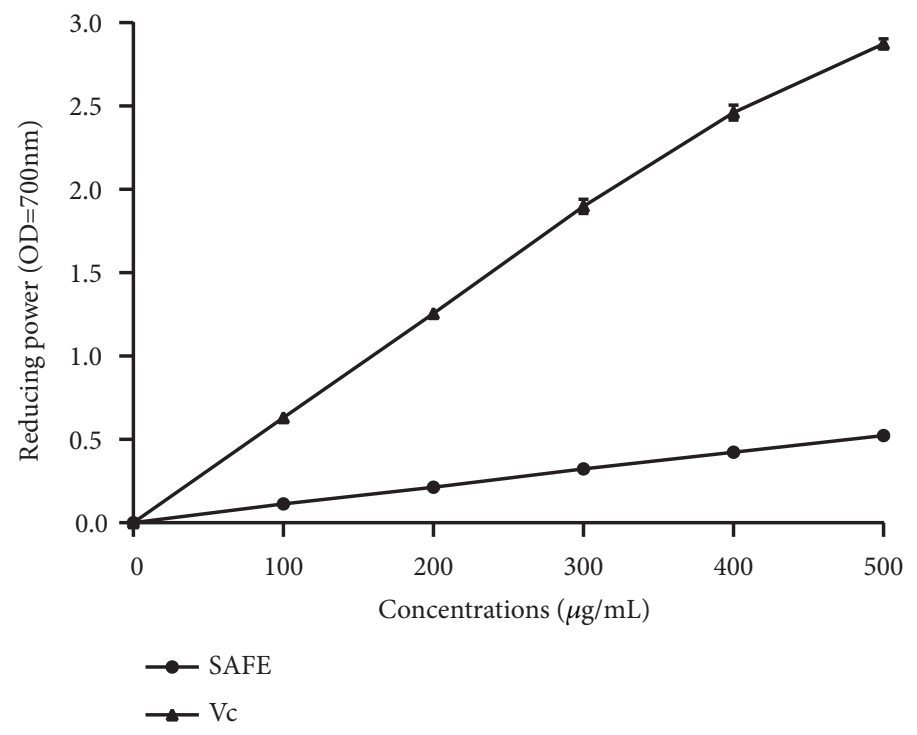

(b)

FIGURE 1: Antioxidant activity of SAFE in vitro. (a) DPPH radical scavenging activity and (b) reducing power. Data are presented as a mean $\pm \mathrm{SD}(\mathrm{n}=3)$.

However, SAFE treatment significantly attenuated APAPinduced GSH depletion and decreased GSH-Px activity $(p$ $<0.01)$. Likewise, the CAT activity and T-AOC level also decreased by $32.63 \%$ and $35.14 \%$ in APAP-treated mice, and CAT activity increased by $30.47 \%, 43.36 \%$, and $46.88 \%$ with SAFE $(100,200$, and $400 \mathrm{mg} / \mathrm{kg})$ treatment dose-dependently $(p<0.01)$, and T-AOC levels increased by $29.17 \%, 33.33 \%$, and $43.75 \%$ with SAFE treatment $(100,200$, and $400 \mathrm{mg} / \mathrm{kg})$ as compared with APAP control $(p<0.05$ or $p<0.01)$. Hepatic MDA levels also increased significantly by $48.99 \%$ in APAP-treated group but decreased significantly with SAFE treatment. 


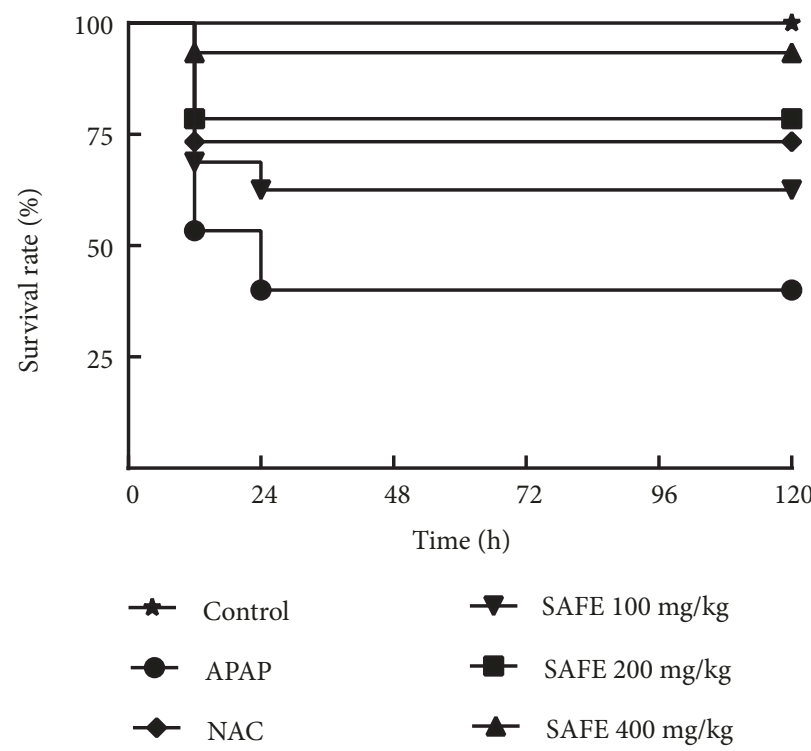

FIGURE 2: SAFE attenuated APAP-induced high mortality rate. The survival rate was expressed as Kaplan-Meier curves followed by the logrank Mantel-Cox test for comparison among curves $(n=15)$. Survival rate was significantly lower in APAP group mice compared to that in control, $200 \mathrm{mg} / \mathrm{kg} \mathrm{SAFE}$ and $400 \mathrm{mg} / \mathrm{kg}$ SAFE groups $(p<0.01, p<0.05$ and $p<0.01$, respectively).

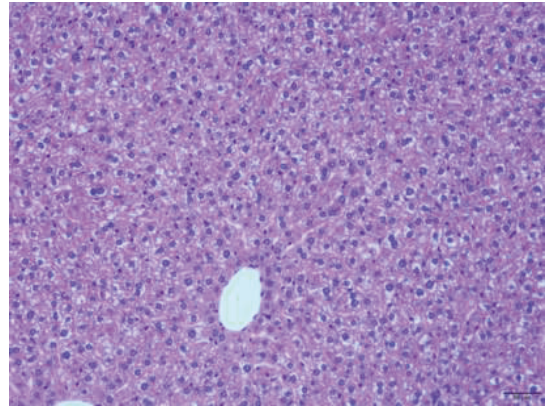

(a)

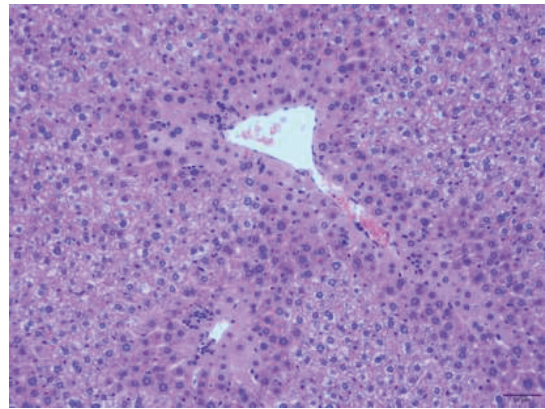

(d)

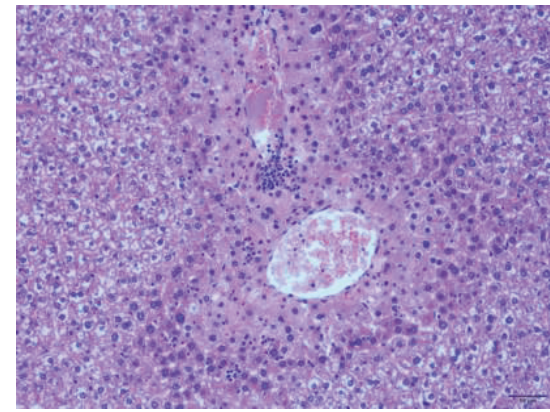

(b)

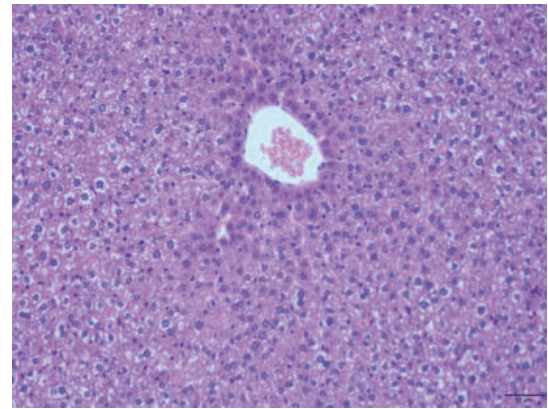

(e)

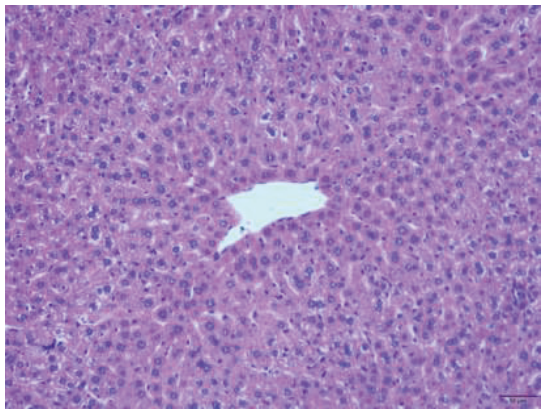

(c)

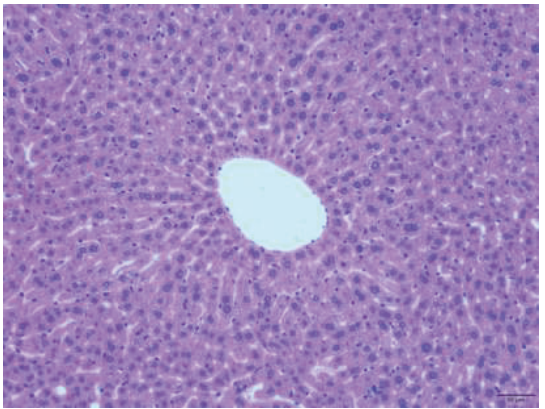

(f)

FIGURE 3: SAFE relieved hepatic histopathological damage in APAP-treated mice. (a) Control; (b) APAP; (c) NAC; (d) 100 mg/kg of SAFE; (e) $200 \mathrm{mg} / \mathrm{kg}$ of SAFE; (f) $400 \mathrm{mg} / \mathrm{kg}$ of SAFE. Scale bar: $50 \mu \mathrm{m}$.

3.3.5. SAFE Attenuated APAP-Induced Inflammation. As shown in Figure 7, the hepatic TNF- $\alpha$ and IL-6 levels increased significantly after APAP exposure. However, SAFE treatment significantly decreased the over production of TNF- $\alpha$ and IL-6 $(p<0.05)$. Furthermore, the MPO activity was also tested and results were shown in Figure 6. A single dose of APAP significantly elevated MPO activity in liver when compared with the control group $(6.57 \pm 0.94$ vs. 3.34 $\pm 0.24 \mathrm{U} / \mathrm{g}, p<0.01)$. But, SAFE treatment (200 and 400 $\mathrm{mg} / \mathrm{kg}$ ) significantly decreased the MPO activities compared with APAP group, respectively $(4.90 \pm 0.48$ vs. $6.57 \pm 0.94$ $\mathrm{U} / \mathrm{g}, p<0.05 ; 3.91 \pm 0.72$ vs. $6.57 \pm 0.94 \mathrm{U} / \mathrm{g}, p<0.01)$. 


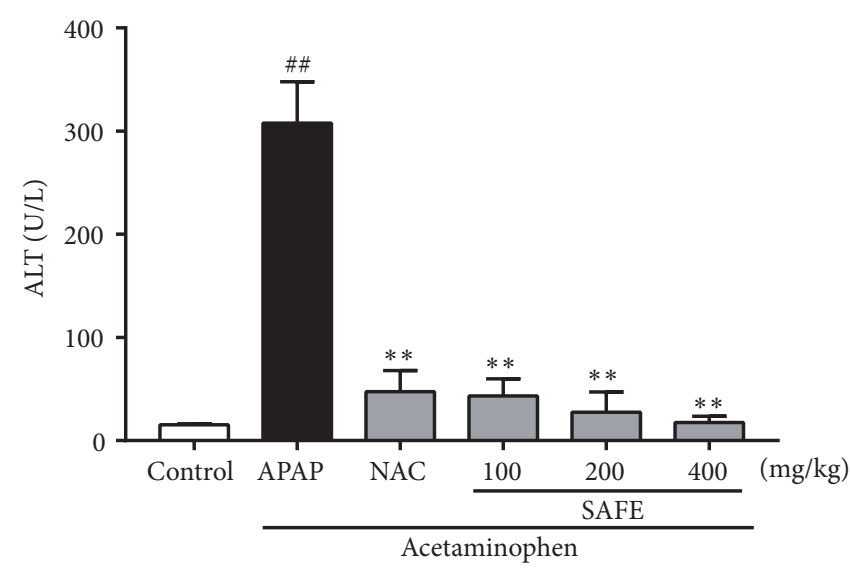

(a)

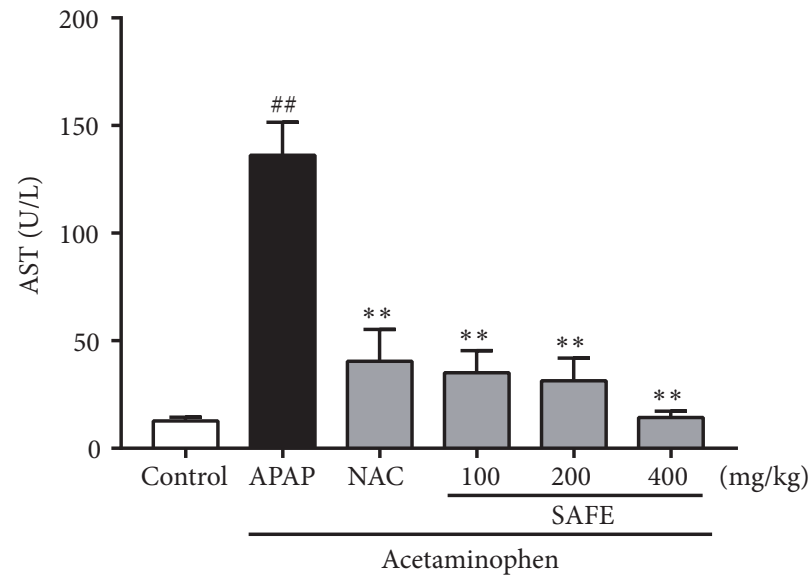

(b)

Figure 4: SAFE inhibited ALT (a) and AST (b) levels in serum. Data are presented as a mean \pm SD ( $\mathrm{n}=8),{ }^{\# \#} p<0.01$ vs. control group; $* p<$ 0.05 or $* * p<0.01$ vs. APAP group.

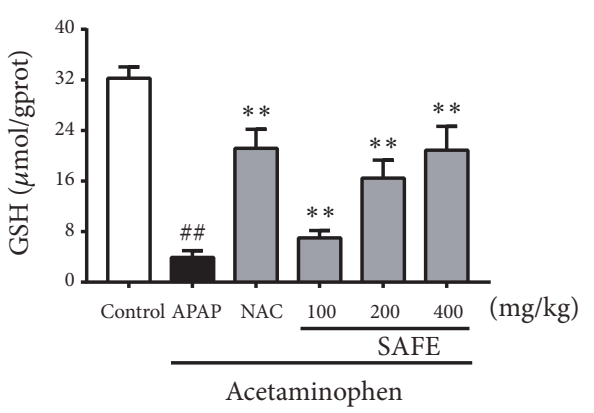

(a)

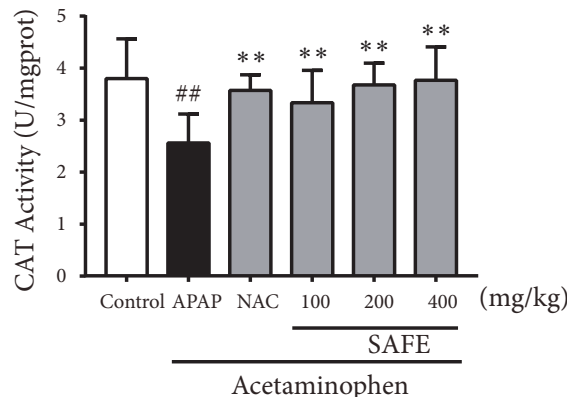

(c)

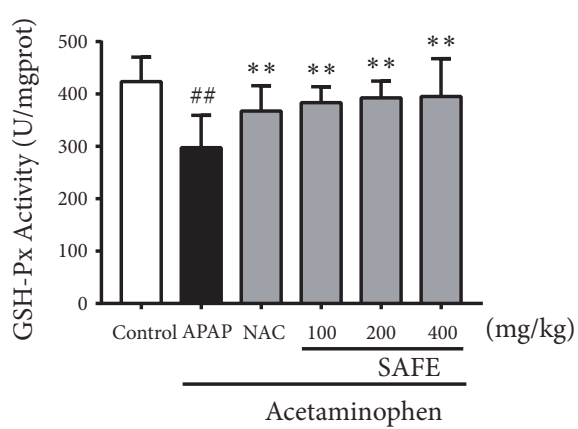

(b)

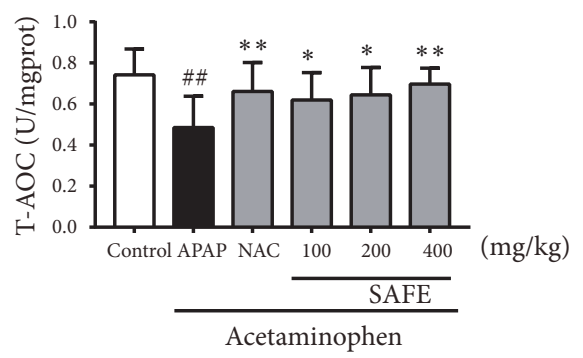

(d)

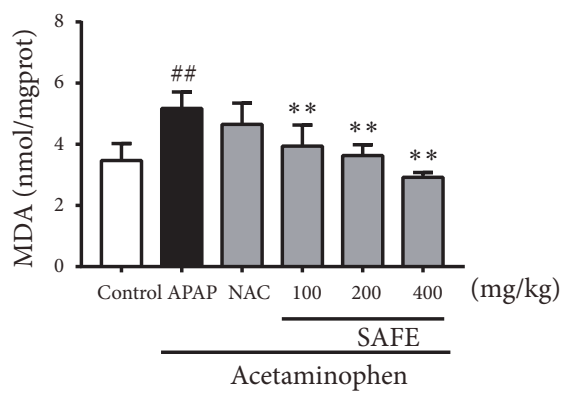

(e)

FIGURE 5: SAFE restrained APAP-induced liver oxidative stress in APAP-treated mice. (a) GSH; (b) GSH-Px; (c) CAT; (d) T-AOC; and (e) MDA. Data are presented as a mean $\pm \mathrm{SD}(\mathrm{n}=8),{ }^{\# \#} p<0.01$ vs. control group; $* p<0.05$ or $* * p<0.01$ vs. APAP group. 


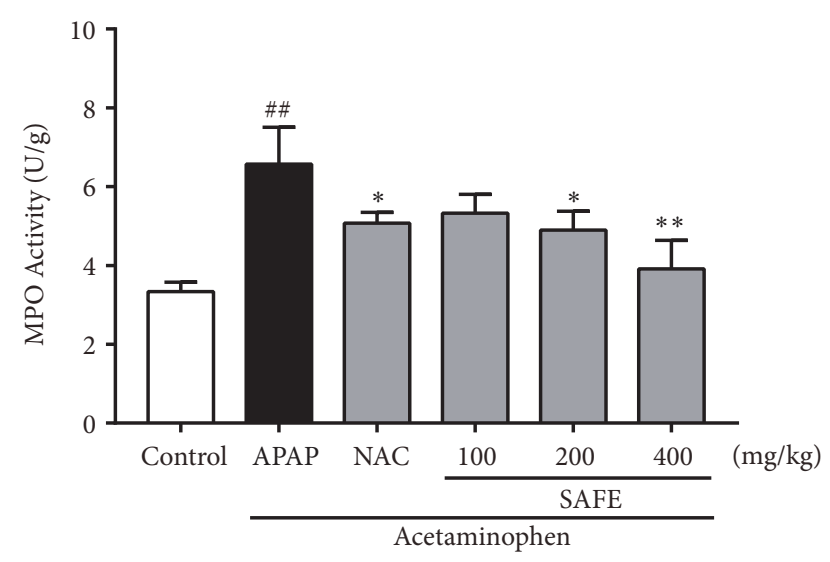

FIgURE 6: SAFE suppressed APAP-induced MPO regulation. Data are presented as a mean $\pm \mathrm{SD}(\mathrm{n}=8),{ }^{\# \#} p<0.01$ vs. control group; $* p$ $<0.05$ or $* * p<0.01$ vs. APAP group.

\section{Discussion}

Recently, natural products from plants have been manifested to play basic roles in human health care and liver diseases on account of their biological activities [43]. Among them, phytochemicals, the bioactive ingredients derived from plants, have beneficial effects on the prevention and treatment of diseases [11]. S. apetala is a dominant exotic mangroves species introduced to China and its fruits have high nutritional value and exhibit various bioactivities [11]. In this study, the phytochemical constituents and the antioxidant activity as well as the hepatoprotective effect of $S$. apetala fruit extracts on liver injury caused by APAP in mice were evaluated.

It is well known that phenols, flavonoids, tannins, and carbohydrate are bioactive components of plants which show high antioxidant activity $[11,30,44]$. In this study, the results supported by Anha Afrin Shefa et al. [16] showed that different chemical compounds were present in SAFE, such as flavonoids, phenols, tannins, steroids, alkaloids, carbohydrates, and so on. The contents of total phenol and flavonoid from SAFE were lower than flower extract of Millingtonia hortensis Linn, a plant containing an abundant resource of flavonoids [45], while being higher than other mangrove plants [46, 47]. Moreover, SAFE showed lower condensed tannin content compared with true mangrove plants in South China [48]. And the carbohydrate content of SAFE was high in this study. This finding was similar with the published report [11].

Reactive oxygen species (ROS) are the inevitable products of oxidative metabolic processes, which lead to oxidative stress and cause liver damage that can be alleviated by antioxidants [49]. Hence, it is necessary to find safe and effective antioxidants. It has been reported that the capacity of natural products including phenols, flavonoids, polysaccharides, etc. in treating liver injury may be due to its antioxidant activity $[44,50-52]$. In order to study the antioxidant activity of natural products, different assays based on chemical methods such as DPPH radical scavenging activity and reducing power have been applied $[53,54]$. Owing to more stability, simplicity, and rapidity, DPPH assay was generally used to evaluate the free radical scavenging capacity of natural antioxidant [55]. In present study, SAFE exhibited scavenging activity on $\mathrm{DPPH}$ radical, which was in accordance with that reported by Hossain et al. [56]. Moreover, the reducing power was also determined to evaluate SAFE antioxidant capacity in vitro. The results showed that reducing property of SAFE increased in a dose manner. Although the incompetency of SAFE to compete with positive controls (ascorbic acid in DPPH radical scavenging ability and reducing power), it did possess antioxidant activity and may be regarded as potential natural antioxidant. The antioxidant capacities of SAFE might be attributed to the presence of phytochemicals such as phenols, flavonoids, tannins, and carbohydrates, which were in accordance with the researches of Raja et al. [30] and Hossain et al. [11].

Drug-induced liver injury is a main cause of liver diseases in clinic and the incidence of drug-induced liver injury seems to be on the rise along with the increase in the number of new drugs available [57]. Among the drug-induced liver injury, APAP-induced liver injury has taken the lead [58]. APAP is safe antipyretic analgesics in therapeutic doses but is a major exposed factor in acute liver injury once over dose [59]. An overdose APAP will bring about hepatocellular injury that leads to the elevation of serum aminotransferases level; hence serum levels of ALT and AST among liver enzymes are widely used as indicators of liver function [43, 60, 61]. In our study, the significantly increased serum aminotransferases levels proved the success of establishing APAP-induced liver injury model in mice. And SAFE pretreatment suppressed serum levels of ALT and AST, which also manifested its hepatoprotective capacity. The improvement of survival rates and attenuation of liver histological damage in APAPinduced liver injury model further validated that SAFE could alleviate liver injury. These results were confirmed by other previous findings, the increase of survival rate, decrease of serum markers, and alleviation of liver histological damage in APAP-induced liver damage after the treatment of different plant extracts $[62,63]$. Normally, clinical dose of APAP mainly binds to glucuronic acid or sulfate in the liver and then is excreted into plasma or bile $[64,65]$. However, a small proportion of APAP administered at clinical dose can be rapidly metabolized by cytochrome P450 (CYP) system in liver and subsequently forms available reactive metabolite, $\mathrm{N}$-acetyl-p-benzoquinone imine (NAPQI), combined with GSH and detoxified to innoxious mercaptoacetic acid in physiological conditions [66]. Nevertheless, a noxious dose of APAP produces excessive NAPQI that consumes GSH by reacting with it and binding cysteine groups on hepatocytes, which results in the formation of protein adducts by binding redundant NAPQI and proteins in a covalent binding manner [67]. The formation of protein adducts means excess generation of reactive oxygen species and peroxynitrite beyond the antioxidant recovery system and finally leads to hepatocellular injury [68]. Wang et al. [69] proved that Seabuckthorn Berry polysaccharide pretreatment could alleviate APAP-induced oxidative stress by restoring GSH and increasing the activities of antioxidant enzymes. In this study, the hepatic GSH level and GSH-Px activity 


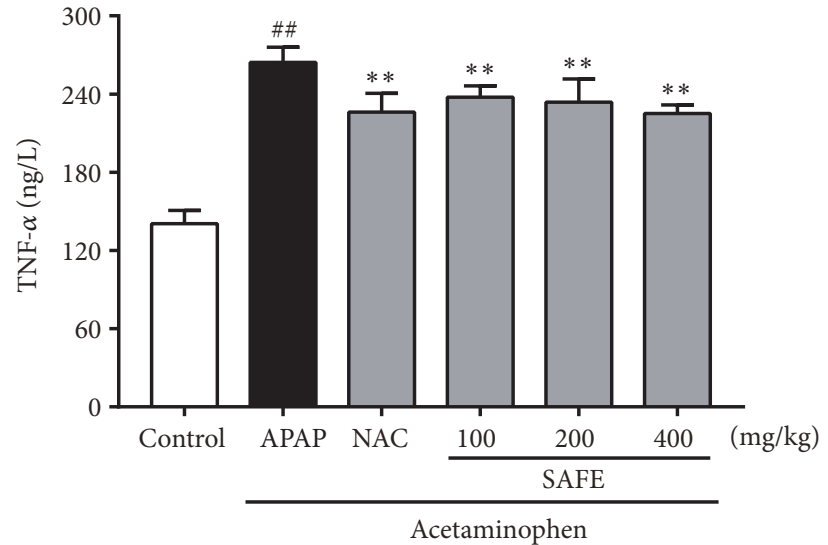

(a)

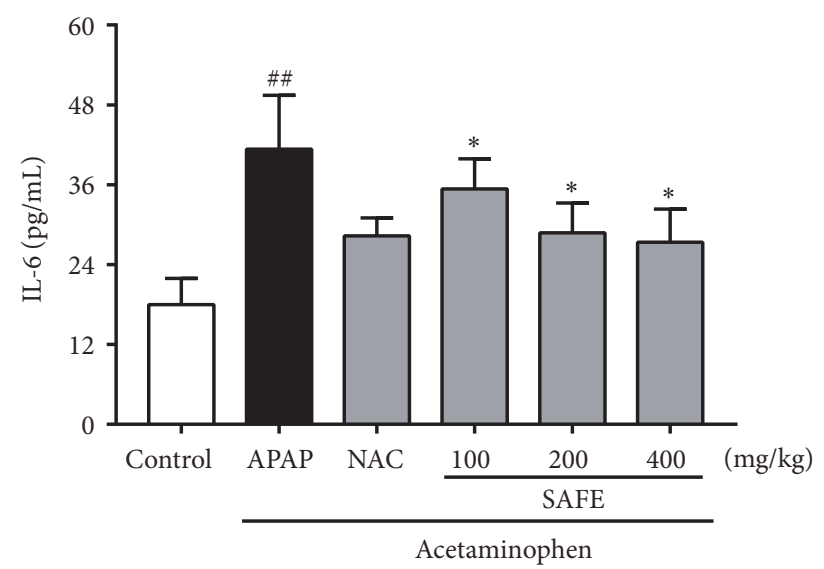

(b)

FIGURE 7: SAFE inhibited APAP-induced inflammation in mice. The level of TNF- $\alpha$ (a) and IL-6 (b) was measured. Data are presented as a mean $\pm S D(n=8),{ }^{\# \#} p<0.01$ vs. control group; $* p<0.05$ or $* * p<0.01$ vs. APAP group.

increased with SAFE treatment compared with APAP group. Moreover, SAFE treatment also increased CAT activity and T-AOC level, as well as decreasing MDA level. These results proved that SAFE attenuated APAP-induced liver injury by alleviating oxidant stress and improving antioxidant enzymes activity, which were also in accordance with other reports $[33,70,71]$.

In addition, a quantity of inflammatory mediators such as cytokines and chemokines is also involved in the toxicity of APAP [67]. Several reports declared that APAP-induced liver injury might be attenuated by decreasing oxidative stress and inhibiting inflammatory response [72-74]. Alleviation of APAP-induced liver injury was able to be achieved by suppressing the inflammatory cytokines production, such as TNF- $\alpha$ and IL-6 [32, 75]. Salem et al. [33] demonstrated that Phyllanthus muellarianus aqueous leaf extract significantly reversed the increase of TNF- $\alpha$ and IL- 6 in APAP-induced liver injury. In the present study, SAFE could alleviate inflammatory response in APAP-induced liver injury model via downregulating the levels of TNF- $\alpha$, IL- 6 , and MPO activity, which might suggest that the anti-inflammatory effect was involved in the hepatoprotective effect of SAFE. Taken together, the study demonstrated that SAFE had the hepatoprotective effect against liver injury through alleviating oxidative stress and inflammatory response. However, it remains to be solved about the further mechanism of SAFE against APAP-induced liver injury.

\section{Conclusion}

In summary, the fruit extract obtained from S. apetala demonstrated the antioxidant activity, which might be related to its phenols, flavonoids, tannins, and carbohydrates contents. The pretreatment of SAFE exerted significant protective effects against APAP-induced acute liver injury and this may be associated with suppressing oxidative stress or inflammation. The findings of this present study support the fact that $S$. apetala is potential to be hepatic protective drug in the future. The actual bioactive components and underlying mechanisms of the hepatoprotective effect of $S$. apetala will be further in-depth study.

\section{Data Availability}

The data used to support the findings of this study are available from the corresponding author upon request.

\section{Conflicts of Interest}

The authors declare no conflicts of interest.

\section{Authors' Contributions}

Jingjing Liu and Dandan Luo contributed equally to this work.

\section{Acknowledgments}

This work was supported by grants from National Key R\&D Program of China (no. 2017YFC0506200), Guangdong Forestry Science and Technology Innovation Program (no. 2016KJCX026), Science and Technology Development Special Project of Guangdong Province (no. 2017A050506044), Guangdong Provincial Department of Education Feature Innovation Project (no. 2016KTSCX018), and Science and Technology Project of Guangzhou (no. 201704030028).

\section{References}

[1] H. Jaeschke, "Acetaminophen: dose-dependent drug hepatotoxicity and acute liver failure in patients," Digestive Diseases, vol. 33, no. 4, pp. 464-471, 2015.

[2] M. Maes, M. Vinken, and H. Jaeschke, "Experimental models of hepatotoxicity related to acute liver failure," Toxicology and Applied Pharmacology, vol. 290, pp. 86-97, 2016. 
[3] H. Jaeschke, C. D. Williams, A. Ramachandran, and M. L. Bajt, "Acetaminophen hepatotoxicity and repair: the role of sterile inflammation and innate immunity," Liver International, vol. 32, no. 1, pp. 8-20, 2012.

[4] M. R. McGill, M. R. Sharpe, C. D. Williams, M. Taha, S. C. Curry, and H. Jaeschke, "The mechanism underlying acetaminophen-induced hepatotoxicity in humans and mice involves mitochondrial damage and nuclear DNA fragmentation," The Journal of Clinical Investigation, vol. 122, no. 4, pp. 1574-1583, 2012.

[5] K. Rhodes and A. Braakhuis, "Performance and side effects of supplementation with $\mathrm{n}$-acetylcysteine: a systematic review and meta-analysis," Sports Medicine, vol. 47, no. 8, pp. 1619-1636, 2017.

[6] M. G Jahromi, F. Nabavizadeh, J. Vahedian, H. Nahrevanian, A.R. Dehpour, and A. Zare-Mehrjardi, "Protective effect of ghrelin on acetaminophen-induced liver injury in rat," Peptides, vol. 31, no. 11, pp. 2114-2117, 2010.

[7] A. K. Gupta, G. M. Chan, H. A. Greller, and M. K. Su, "NAC: Still the way to go," Critical Care, vol. 13, no. 3, 2009.

[8] N. S. Uchida, S. E. Silva-Filho, R. P. Aguiar et al., "Protective effect of cymbopogon citratus essential oil in experimental model of acetaminophen-induced liver injury," American Journal of Chinese Medicine, vol. 45, no. 3, pp. 515-532, 2017.

[9] L. Lahouar, S. El-Bok, and L. Achour, "Therapeutic potential of young green barley leaves in prevention and treatment of chronic diseases: an overview," American Journal of Chinese Medicine, vol. 43, no. 7, pp. 1311-1329, 2015.

[10] J. K. Patra, S. K. Das, and H. Thatoi, "Phytochemical profiling and bioactivity of a mangrove plant, Sonneratia apetala, from Odisha Coast of India," Chinese Journal of Integrative Medicine, vol. 21, no. 4, pp. 274-285, 2015.

[11] S. J. Hossain, M. Iftekharuzzaman, M. A. Haque et al., "Nutrient compositions, antioxidant activity, and common phenolics of Sonneratia apetala (Buch.-Ham.) fruit," International Journal of Food Properties, vol. 19, no. 5, pp. 1080-1092, 2015.

[12] S. J. Hossain, T. Pervin, and S. A. Suma, "Effects of cooking methods at different time durations on total phenolics and antioxidant activities of fresh and dried-stored fruits of Sonneratia apetala (Buch.-Ham.)," International Food Research Journal, vol. 23, no. 2, pp. 556-563, 2016.

[13] H. Ren, H. F. Lu, W. J. Shen et al., "Sonneratia apetala Buch.Ham in the mangrove ecosystems of China: An invasive species or restoration species?" Ecological Engineering, vol. 35, no. 8, pp. 1243-1248, 2009.

[14] M. Jia, Z. Wang, L. Li et al., "Mapping China's mangroves based on an object-oriented classification of Landsat imagery," Wetlands, vol. 34, no. 2, pp. 277-283, 2014.

[15] B. Liao, S. Zheng, Y. Cheng, M. Li, and Y. Li, "Biological characteristics and ecological adaptability for non-indigenous mangrove species Sonneratia apetala," Chinese Journal of Ecology, vol. 23, no. 1, pp. 10-15, 2004.

[16] A. A. Shefa, F. S. Baishakhi, S. Islam, and S. K. Sadhu, "Phytochemical and pharmacological evaluation of fruits of Sonneratia apetala," Global Joural of Medical Research: B, vol. 14, no. 3, pp. 1-6, 2014.

[17] M. A. H. Mollik, M. S. H. Hossan, A. K. Paul, M. TaufiqUr-Rahman, R. Jahan, and M. Rahmatullah, "A comparative analysis of medicinal plants used by folk medicinal healers in three districts of Bangladesh and inquiry as to mode of selection of medicinal plants," Ethnobotany Research and Applications, vol. 8, pp. 195-218, 2010.
[18] W. M. Bandaranayake, "Bioactivities, bioactive compounds and chemical constituents of mangrove plants," Wetlands Ecology and Management, vol. 10, no. 6, pp. 421-452, 2002.

[19] V. P. Teja and K. Ravishankar, "Preliminary phytochemical investigation and in vitro antimicrobial activity of ethanolic extract of Sonneratia apetala plant," International Research Journal of Pharmacy, vol. 4, no. 6, pp. 84-87, 2013.

[20] Q. F. Ji, W. H. Lin, J. Li et al., "Chemical investingation of Chinese mangrove Sonneratia apetala II," China Journal of Chinese Materia Medica, vol. 30, no. 16, pp. 1258-1260, 2005.

[21] W. M. Bandaranayake, "Traditional and medicinal use of mangrove," Mangroves and Salt Marshes, vol. 2, no. 3, pp. 133148, 1998.

[22] D. Jaimini, C. Sarkar, A. A. Shabnam, and B. L. Jadhav, "Evaluation of antibacterial properties of mangrove plant Sonneratia apetala buch. ham leaf," World Applied Sciences Journal, vol. 14, no. 11, pp. 1683-1686, 2011.

[23] S. P. Mun, M. S. Jahan, A. Al-Maruf, and D. A. N. Chowdhury, "Chemical characterization of six mangrove species in Bangladesh," Wood Science and Technology, vol. 45, no. 2, pp. 281-288, 2011.

[24] H. S. Lin, W. D. Song, J. Wu, D. Z. Chen, and L. Sha, "Analysis of fatty acids constituents in the leaves and gains of Sonneratia apetala," Fujian Analysis \& Testing, vol. 18, no. 3, pp. 5-9, 2009.

[25] X. X. Yi, J. Y. Li, C. H. Gao, Q. Zhang, W. H. Zhou, and J. G. Deng, "Antioxidant activity of alcohol extract and different polar parts of Sonneratia apetala fruits," Science \& Technology of Food Industry, vol. 38, no. 19, pp. 27-30, 2017.

[26] L. L. Cao, H. Y. Tian, Y. S. Wang, X. F. Zhou, R. W. Jiang, and Y. H. Liu, "Chemical constituents in the fruits of mangrove plant Sonneratia apetala Buch. Ham," Journal of Tropical Oceanography, vol. 34, no. 1, pp. 77-82, 2015.

[27] C. Nichita, G. Neagu, V. Vulturescu et al., "Correlation between antioxidant activity and hepatoprotective effect of a vegetal bioproduct," Molecular Crystals and Liquid Crystals, vol. 523, pp. 228-235, 2010.

[28] A. M. Larson, "Acetaminophen hepatotoxicity," Clinics in Liver Disease, vol. 11, no. 3, pp. 525-548, 2007.

[29] S. Sen, B. De, N. Devanna, and R. Chakraborty, "Hepatoprotective and antioxidant activity of Leea asiatica leaves against acetaminophen-induced hepatotoxicity in rats," Tang [Humanitas Medicine], vol. 4, no. 3, p. 18, 2014.

[30] R. Serairi-Beji, W. Aidi Wannes, A. Hamdi et al., "Antioxidant and hepatoprotective effects of Asparagus albus leaves in carbon tetrachloride-induced liver injury rats," Journal of Food Biochemistry, vol. 42, no. 1, Article ID el2433, 2017.

[31] J.-Y. Zhang, S.-D. Song, Q. Pang et al., "Hydrogen-rich water protects against acetaminophen-induced hepatotoxicity in mice," World Journal of Gastroenterology, vol. 21, no. 14, pp. 4195-4209, 2015.

[32] W.-P. Jiang, S.-S. Huang, Y. Matsuda et al., "Protective effects of tormentic acid, a major component of suspension cultures of eriobotrya japonica cells, on acetaminophen-induced hepatotoxicity in mice," Molecules, vol. 22, no. 5, article 830, 2017.

[33] T. O. Ajiboye, F. M. Ahmad, A. O. Daisi et al., "Hepatoprotective potential of Phyllanthus muellarianus leaf extract: Studies on hepatic, oxidative stress and inflammatory biomarkers," Pharmaceutical Biology, vol. 55, no. 1, pp. 1662-1670, 2017.

[34] J. B. Harborne, "Tony Swain and phytochemical methods," Phytochemistry, vol. 49, no. 5, pp. 1163-1164, 1998. 
[35] I. Orhan and O. Üstün, "Determination of total phenol content, antioxidant activity and acetylcholinesterase inhibition in selected mushrooms from Turkey, Journal of Food Composition and Analysis, vol. 24, no. 3, pp. 386-390, 2011.

[36] S. A. Baba and S. A. Malik, "Determination of total phenolic and flavonoid content, antimicrobial and antioxidant activity of a root extract of Arisaema jacquemontii Blume," Journal of Taibah University for Science, vol. 9, no. 4, pp. 449-454, 2015.

[37] P. Matić, M. Sabljić, and L. Jakobek, "Validation of Spectrophotometric Methods for the Determination of Total Polyphenol and Total Flavonoid Content," Journal of AOAC International, vol. 100, no. 6, pp. 1795-1803, 2017.

[38] T. Masuko, A. Minami, N. Iwasaki, T. Majima, S.-I. Nishimura, and Y. C. Lee, "Carbohydrate analysis by a phenol-sulfuric acid method in microplate format," Analytical Biochemistry, vol. 339, no. 1, pp. 69-72, 2005.

[39] D. Y. Zhang, S. J. Li, Q. P. Xiong, C. X. Jiang, and X. P. Lai, "Extraction, characterization and biological activities of polysaccharides from Amomum villosum," Carbohydrate Polymers, vol. 95, no. 1, pp. 114-122, 2013.

[40] L. L. Cai, S. S. Zou, D. P. Liang, and L. B. Luan, "Structural characterization, antioxidant and hepatoprotective activities of polysaccharides from Sophorae tonkinensis Radix," Carbohydrate Polymers, vol. 184, pp. 354-365, 2018.

[41] Z. F. Zhang, G. Y. Lv, W. Q. He, L. G. Shi, H. J. Pan, and L. F. Fan, "Effects of extraction methods on the antioxidant activities of polysaccharides obtained from Flammulina velutipes," Carbohydrate Polymers, vol. 98, no. 2, pp. 1524-1531, 2013.

[42] G. S. Lin, D. D. Luo, J. J. Liu et al., "Hepatoprotective effect of polysaccharides isolated from Dendrobium officinale against acetaminophen-induced liver injury in mice via regulation of the Nrf2-Keap1 signaling pathway," Oxidative Medicine and Cellular Longevity, vol. 2018, Article ID 6962439, 10 pages, 2018.

[43] N. S. Uchida, S. E. Silva-Filho, G. F. E. Cardia et al., "Hepatoprotective effect of citral on acetaminophen-induced liver toxicity in mice," Evidence-Based Complementary and Alternative Medicine, vol. 2017, Article ID 1796209, 9 pages, 2017.

[44] A. Pardede, M. Adfa, A. Juliari Kusnanda, M. Ninomiya, and M. Koketsu, "Flavonoid rutinosides from Cinnamomum parthenoxylon leaves and their hepatoprotective and antioxidant activity," Medicinal Chemistry Research, vol. 26, no. 9, pp. 2074-2079, 2017.

[45] S. Babitha, D. Banji, and O. J. F. Banji, "Antioxidant and hepatoprotective effects of flower extract of Millingtonia hortensis Linn. on carbon tetrachloride induced hepatotoxicity," Journal of Pharmacy and Bioallied Sciences, vol. 4, no. 4, pp. 307-312, 2012.

[46] S.-S. Suh, J. Hwang, M. Park, H.-S. Park, and T.-K. Lee, "Phenol content, antioxidant and tyrosinase inhibitory activity of mangrove plants in Micronesia," Asian Pacific Journal of Tropical Medicine, vol. 7, no. 7, pp. 531-535, 2014.

[47] Y. Y. Zheng, S. H. Zhang, R. Liu, M. Wang, W. T. Wu, and B. P. Ye, "Principal component analysis of environmental factors on the production of total flavonoids in mangrove plant, Bruguiera gymnorhiza," Chinese Journal of Natural Medicines, vol. 6, no. 5, pp. 362-366, 2008.

[48] Y. Wang, H. W. Zhu, and N. F. Y. Tam, "Polyphenols, tannins and antioxidant activities of eight true mangrove plant species in South China," Plant and Soil, vol. 374, no. 1-2, pp. 549-563, 2014.

[49] M. Sobeh, M. F. Mahmoud, M. A. O. Abdelfattah, H. A. ElBeshbishy, A. M. El-Shazly, and M. Wink, "Albizia harveyi: phytochemical profiling, antioxidant, antidiabetic and hepatoprotective activities of the bark extract," Medicinal Chemistry Research, vol. 26, no. 12, pp. 3091-3105, 2017.

[50] M. Yimam, P. Jiao, M. Hong, and Q. Jia, "Hepatoprotective Activity of an Herbal Composition, MAP, a Standardized Blend Comprising Myristica fragrans, Astragalus membranaceus, and Poria cocos," Journal of Medicinal Food, vol. 19, no. 10, pp. 952960, 2016.

[51] A. Ved, A. Gupta, and A. Rawat, "Antioxidant and hepatoprotective potential of phenol-rich fraction of Juniperus communis Linn. leaves," Pharmacognosy Magazine, vol. 13, no. 49, pp. 108113, 2017.

[52] C. M. Zhou, S. J. Yin, Z. F. Yu et al., "Preliminary characterization, antioxidant and hepatoprotective activities of polysaccharides from Taishan Pinus massoniana pollen," Molecules, vol. 23, no. 2, article 281, 2018.

[53] C. López-Alarcón and A. Denicola, "Evaluating the antioxidant capacity of natural products: a review on chemical and cellularbased assays," Analytica Chimica Acta, vol. 763, pp. 1-10, 2013.

[54] J. L. Fan, Z. W. Wu, T. H. Zhao et al., "Characterization, antioxidant and hepatoprotective activities of polysaccharides from Ilex latifolia Thunb," Carbohydrate Polymers, vol. 101, no. 1, pp. 990-997, 2014.

[55] C. Shi, X. C. Zhao, Z. H. Liu, R. Z. Meng, X. R. Chen, and N. Guo, "Antimicrobial, antioxidant, and antitumor activity of epsilon-poly-L-lysine and citral, alone or in combination," Food \& Nutrition Research, vol. 60, Article ID 31891, 2016.

[56] S. J. Hossain, M. H. Basar, B. Rokeya, K. M. T. Arif, M. S. Sultana, and M. H. Rahman, "Evaluation of antioxidant, antidiabetic and antibacterial activities of the fruit of Sonneratia apetala (Buch.Ham.)," Oriental Pharmacy and Experimental Medicine, vol. 13, no. 2, pp. 95-102, 2013.

[57] H. Takikawa, "Recent status of drug-induced liver injury," Hepatology Research, vol. 39, no. 1, pp. 1-6, 2009.

[58] H. C. Spangenberg, "Drug-induced liver diseases," Deutsche Medizinische Wochenschrift, vol. 141, no. 23, pp. 1688-U63, 2016.

[59] M. Coen, "Metabolic phenotyping applied to pre-clinical and clinical studies of acetaminophen metabolism and hepatotoxicity," Drug Metabolism Reviews, vol. 47, no. 1, pp. 29-44, 2015.

[60] L. N. Bell, R. Vuppalanchi, P. B. Watkins et al., "Serum proteomic profiling in patients with drug-induced liver injury," Alimentary Pharmacology \& Therapeutics, vol. 35, no. 5, pp. 600-612, 2012.

[61] T. J. Green, M. L. A. Sivilotti, C. Langmann et al., "When do the aminotransferases rise after acute acetaminophen overdose," Clinical Toxicology, vol. 48, no. 8, pp. 787-792, 2010.

[62] O. A. Zargar, R. Bashir, S. A. Ganie, A. Masood, M. A. Zargar, and R. Hamid, "Hepatoprotective Potential of Elsholtzia densa Against Acute and Chronic Models of Liver Damage in Wistar Rats," Drug Research, vol. 68, no. 10, pp. 567-575, 2018.

[63] E. Lin, A. Chagnaadorj, S. Huang, C. Wang, Y. Chiang, and C. Cheng, "Hepatoprotective activity of the ethanolic extract of Polygonum multiflorum Thunb. against oxidative stressinduced liver injury," Evidence-Based Complementary and Alternative Medicine, vol. 2018, Article ID 4130307, 9 pages, 2018.

[64] C. Bunchorntavakul and K. R. Reddy, "Acetaminophen-related Hepatotoxicity," Clinics in Liver Disease, vol. 17, no. 4, pp. 587607, 2013.

[65] J.-R. Noh, Y.-H. Kim, J. H. Hwang et al., "Davallialactone protects against acetaminophen overdose-induced liver injuries in mice," Food and Chemical Toxicology, vol. 58, pp. 14-21, 2013. 
[66] S. Tujios and R. J. Fontana, "Mechanisms of drug-induced liver injury: from bedside to bench," Nature Reviews Gastroenterology \& Hepatology, vol. 8, no. 4, pp. 202-211, 2011.

[67] J. A. Hinson, D. W. Roberts, and L. P. James, "Mechanisms of acetaminophen-induced liver necrosis," Handbook of Experimental Pharmacology, vol. 196, pp. 369-405, 2010.

[68] H. Jaeschke and A. Ramachandran, "Reactive oxygen species in the normal and acutely injured liver," Journal of Hepatology, vol. 55, no. 1, pp. 227-228, 2011.

[69] X. Wang, J. R. Liu, X. H. Zhang et al., "Seabuckthorn berry polysaccharide extracts protect against acetaminophen induced hepatotoxicity in mice via activating the Nrf-2/HO-1-SOD-2 signaling pathway," Phytomedicine, vol. 38, pp. 90-97, 2018.

[70] T. Lakshmi, B. Sri Renukadevi, S. Senthilkumar et al., "Seed and bark extracts of Acacia catechu protects liver from acetaminophen induced hepatotoxicity by modulating oxidative stress, antioxidant enzymes and liver function enzymes in Wistar rat model," Biomedicine \& Pharmacotherapy, vol. 108, pp. 838-844, 2018.

[71] G. A. Salem, A. Shaban, H. A. Diab et al., "Phoenix dactylifera protects against oxidative stress and hepatic injury induced by paracetamol intoxication in rats," Biomedicine \& Pharmacotherapy, vol. 104, pp. 366-374, 2018.

[72] D. Werawatganon, S. Linlawan, K. Thanapirom et al., "Aloe vera attenuated liver injury in mice with acetaminophen-induced hepatitis," BMC Complementary and Alternative Medicine, vol. 14, Article ID 229, 10 pages, 2014.

[73] B. O. Cho, H. H. Yin, C. Z. Fang, S. J. Kim, S. I. Jeong, and S. I. Jang, "Hepatoprotective effect of Diospyros lotus leaf extract against acetaminophen-induced acute liver injury in mice," Food Science and Biotechnology, vol. 24, no. 6, pp. 2205-2212, 2015.

[74] Y. Cai, W. Sun, X.-X. Zhang, Y.-D. Lin, H. Chen, and H. Li, "Osthole prevents acetaminophen-induced liver injury in mice," Acta Pharmacologica Sinica, vol. 39, no. 1, pp. 74-84, 2018.

[75] X. F. Chen, J. Huang, Z. H. Hu, Q. S. Zhang, X. X. Li, and D. B. Huang, "Protective effects of dihydroquercetin on an APAPinduced acute liver injury mouse model," International Journal of Clinical and Experimental Pathology, vol. 10, no. 10, pp.1022310232, 2017. 


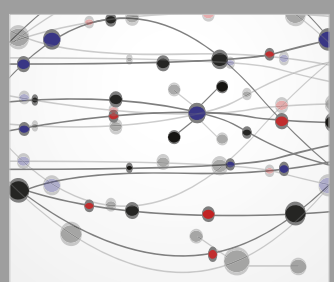

The Scientific World Journal
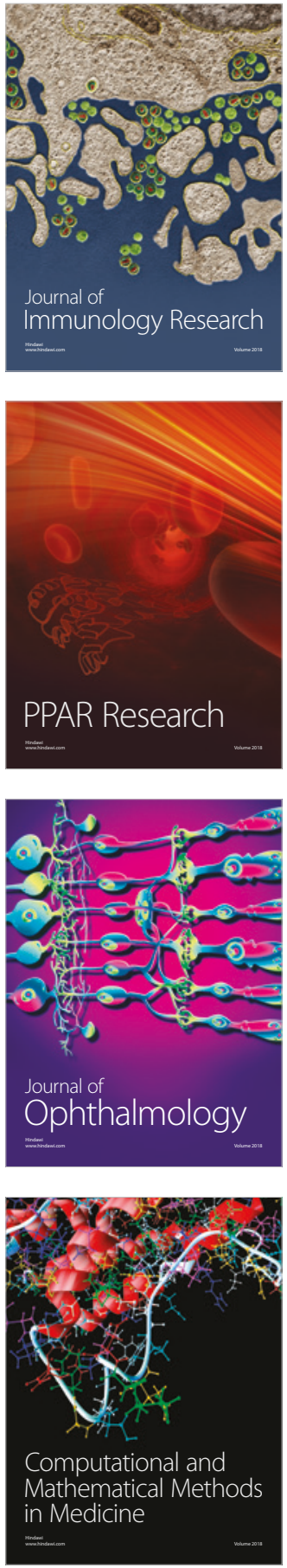

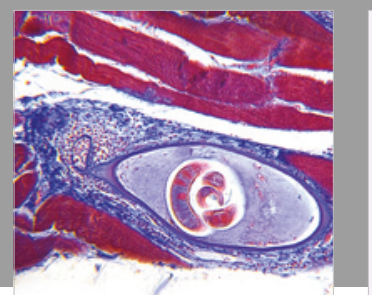

Gastroenterology Research and Practice

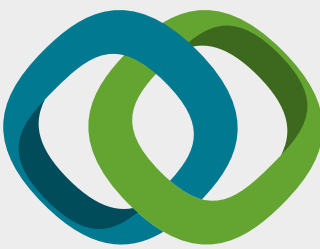

\section{Hindawi}

Submit your manuscripts at

www.hindawi.com
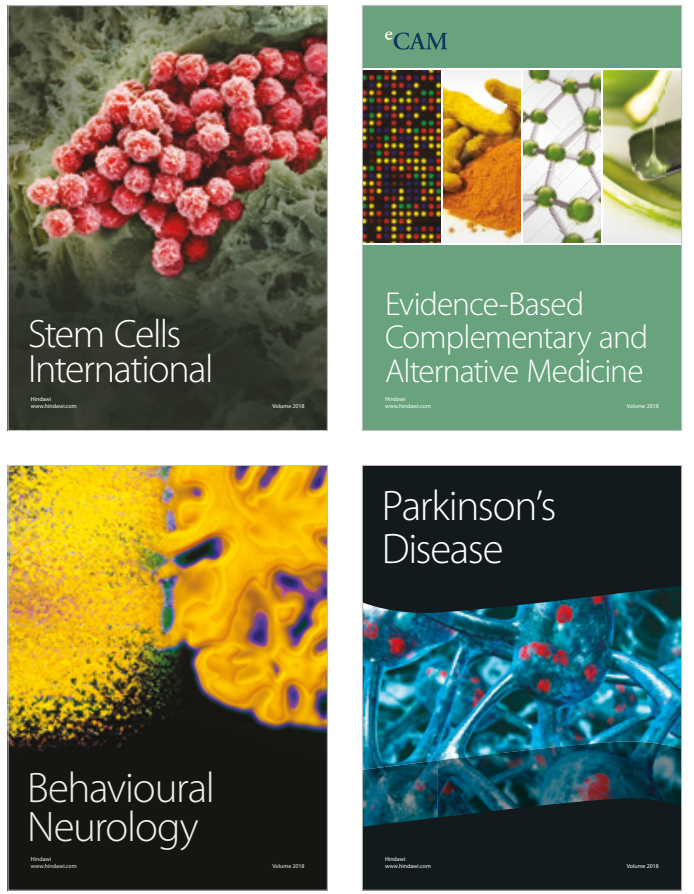

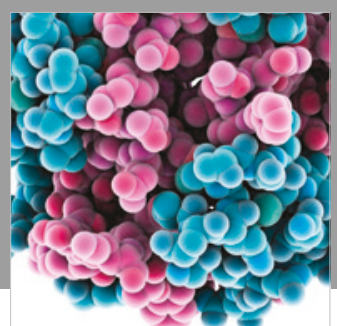

ournal of

Diabetes Research

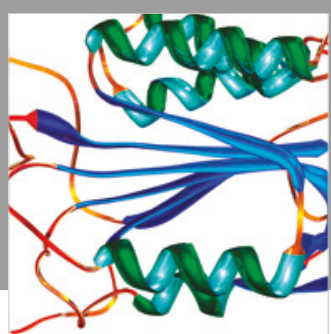

Disease Markers
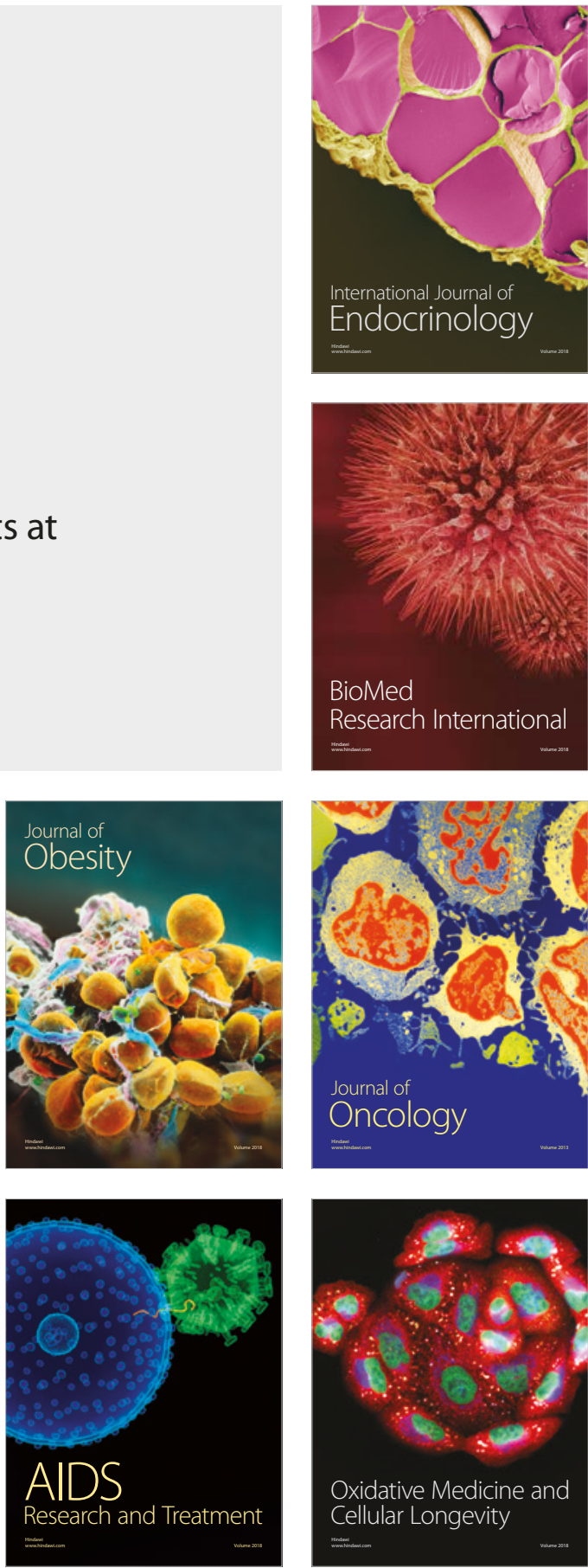